\title{
“Como Quebrar os Padrões Sociais?”: o Racismo no Cotidiano de Jovens Pesquisadores
}

\author{
Luciana Lobo Miranda ${ }^{1}$ \\ ${ }^{1}$ Universidade Federal do Ceará, CE, Brasil. \\ Tadeu Lucas de Lavor Filho ${ }^{1}$ \\ ${ }^{1}$ Universidade Federal do Ceará, CE, Brasil. \\ José Alves de Souza Filho ${ }^{1}$ \\ ${ }^{1}$ Universidade Federal do Ceará, CE, Brasil.
}

\author{
Shirley Dias Gonçalves ${ }^{1}$ \\ ${ }^{1}$ Universidade Federal do Ceará, CE, Brasil. \\ Thalia Araújo Bezerra ${ }^{1}$ \\ ${ }^{1}$ Universidade Federal do Ceará, CE, Brasil. \\ Gabrielle Lima Feitosa ${ }^{1}$ \\ ${ }^{1}$ Universidade Federal do Ceará, CE, Brasil.
}

Resumo: $O$ presente artigo apresenta uma reflexão crítica sobre as questões raciais e o enfrentamento ao racismo na micropolítica do cotidiano escolar. Nosso objetivo foi analisar o processo de construção e execução de uma investigação feita por estudantes do ensino médio sobre a presença e o combate ao racismo institucional em uma escola pública estadual de Fortaleza (CE). Trabalhamos a partir de uma pesquisa-intervenção (PI) articulada ao referencial teórico-metodológico da Critical Participatory Action Research (CPAR), que balizou a construção de uma "pesquisaCOM" com jovens. Desenvolvemos um curso de formação de jovens pesquisadores para construir uma pesquisa com ferramentas metodológicas em que eles fossem protagonistas na construção, aplicação e análise da pesquisa. Percebemos que o tema do enfrentamento ao racismo na micropolítica do cotidiano escolar teve centralidade no processo de pesquisa que os jovens realizaram entre seus pares. Os resultados apontaram que 30,2\% dos secundaristas afirmaram ter sofrido algum tipo de preconceito racial, tais como: preconceito em relação ao cabelo por ser cacheado; ter escutado expressões/apelidos pejorativos por ser negro e não ter boas condições financeiras, além de relatarem não se sentir à vontade para falar sobre o preconceito presente na escola. Assim, a pesquisa realizada pelos jovens, intitulada "Como quebrar os padrões sociais?", contribuiu para a discussão das relações raciais na escola, fomentando deslocamentos na formação de jovens pesquisadores atuantes e implicados no seu cotidiano com a intenção de descolonizar o saber e radicalizar o caráter participativo.

Palavras-chave: Pesquisa-intervenção, Racismo, Jovens pesquisadores, Escola.

\section{"How to Break Social Standards?": Racism in the Daily Lives of Young Researchers}

\begin{abstract}
This article presents a critical reflection on racial issues and the confrontation with racism in the micropolitics of school daily life. Our objective was to analyze the process of construction and execution of an investigation of high school students about the presence and fight against the institutional racism in a state public school of Fortaleza, Ceará. We performed an Intervention Research (IP) in conjunction with the theoretical-methodological framework of Critical Participatory Action Research (CPAR), which guided the construction of a COM research with young people. We created a training course for young researchers to develop research with methodological tools in which they themselves were protagonists in the construction, application andanalysisofresearch.Werealize that thethemeofconfrontingracisminthemicropoliticsofschool daily life was central to the research process that the young people conducted among their peers.
\end{abstract}


The results showed that $30.2 \%$ of high school students said they had suffered some kind of racial prejudice, such as: prejudice against hair because it was curly; having heard pejorative expressions/nicknames for being black and not having good financial conditions, and reporting not feeling comfortable talking about the prejudice present at school. Thus, the study "How to break social standards?" conducted by young people contributed to the discussion of race relations in school by fostering dislocation in the formation of active young researchers and implicated in their daily lives as an intervention to decolonize knowledge and radicalize participatory character.

Keywords: Intervention research, Racism, Young researchers, School.

\title{
“¿Cómo Romper los Estándares Sociales?”: Racismo en la Vida Cotidiana de los Jóvenes Investigadores
}

\begin{abstract}
Resumen: Este artículo presenta una reflexión crítica sobre la temática racial y la confrontación con el racismo en la micropolítica de la vida diaria escolar. Nuestro objetivo fue analizar el proceso de construcción y ejecución de una investigación realizada por estudiantes de secundaria sobre la presencia y la lucha contra el racismo institucional en una escuela pública estadual de Fortaleza, CE. Trabajamos a partir de una Investigación de Intervención (IP) operada con el marco teórico-metodológico de la Investigación de Acción-Participativa Crítica (CPAR), que guio la construcción de una investigaciónCOM con los jóvenes. Desarrollamos un taller de capacitación destinado a jóvenes investigadores para construir investigaciones con herramientas metodológicas en las cuales ellos fueran los protagonistas en la construcción, aplicación y análisis de la investigación. Se observó que confrontar el racismo en la micropolítica de la vida diaria de la escuela fue central en el proceso de investigación que los jóvenes llevaron a cabo entre sus pares. Los resultados mostraron que el 30,2\% de los estudiantes de secundaria dijeron haber sufrido algún tipo de prejuicio racial, como: prejuicio contra el cabello porque era rizado; haber escuchado expresiones peyorativas/apodos por ser negro y no tener buenas condiciones financieras, y por no sentirse cómodo hablando sobre el prejuicio presente en la escuela. Por lo tanto, la investigación “¿Cómo romper los estándares sociales?” realizada por jóvenes contribuyó a la discusión sobre las relaciones raciales en la escuela al fomentar las dislocaciones en la formación de jóvenes investigadores activos e implicados en su vida diaria con la intención de descolonizar el conocimiento y radicalizar el carácter participativo.
\end{abstract}

Palabras clave: Investigación-intervención, Racismo, Jóvenes Investigadores, Escuela.

\section{Introdução}

O presente artigo tem como objetivo analisar o processo de construção e execução de uma investigação de jovens estudantes do ensino médio sobre a presença do racismo no cotidiano de uma escola pública estadual do município de Fortaleza (CE) como parte de uma pesquisa-intervenção operada por pesquisadores do campo da psicologia escolar/ educacional vinculados à graduação e pós-graduação em Psicologia de uma universidade federal. Partimos do projeto de pesquisa intitulado "Educação, modos de subjetivação e formação de jovens pesquisadores da micropolítica do cotidiano escolar", cujo objetivo é problematizar a relação entre juventude e escola pública com base na produção discursiva dos próprios jovens, analisando a construção de pesquisas com estudantes em que eles são pesquisadores desses processos. Com a proposta de pesquisarCOM os jovens, diferentes da tradição positivista de pesquisar sobre, buscamos problematizar com os estudantes os discursos que atravessam o cotidiano escolar, sobretudo, desconstruindo práticas naturalizadas 
ou evidenciando questões e problemas periféricos. Especificamente sobre as questões do racismo, discutimos os impactos (in)visíveis de práticas de segregação e violências étnico-raciais e suas respectivas lutas e combates, que reverberam nas relações intraescolares.

Sobre as (in)visibilizações das questões étnicoraciais, para além da micropolítica escolar que trabalharemos no presente artigo, vale resgatar as discussões molares enquanto as políticas educacionais de estado que fortalecem a institucionalização da luta contra o racismo dentro da dinâmica das instituições escolares. A obrigatoriedade do ensino da história e cultura afro-brasileira encontra-se inserida nas políticas educacionais brasileira. Segundo Abreu e Mattos (2008), os Parâmetros Curriculares Nacionais (PNC), aprovado pelo Ministério da Educação (MEC) em 1996, precederam e prepararam as Diretrizes Curriculares Nacionais para a Educação das Relações Étnico-Raciais e para o Ensino de História e Cultura Afro-Brasileira e Africana, resultantes do crescimento e fortalecimento dos movimentos negros brasileiros e de um novo consenso pedagógico sobre o "mito da democracia racial" no Brasil. Os PNC e as referidas diretrizes são medidas que se relacionam com a diversidade cultural e as políticas de ações afirmativas, ou seja, são políticas que têm um caráter reparatório e de valorização da história e da cultura afro-brasileira. A inserção desses dois aparatos metodológicos no âmbito escolar teve suma importância na descentralização do foco dos estudos em uma cultura branca e com viés europeu, incluindo outras tradições e desmistificando a ideia que a miscigenação do branco, índio e negro tornou o Brasil democrático racialmente. Os PNC e as diretrizes possibilitaram também que os professores trabalhem com os alunos o quanto o preconceito racial, apesar de difuso, ainda ocorre, segregando uma parcela expressiva da sociedade.

Conforme ratifica Aranda (2011), a importância da institucionalização, dentro das diretrizes curriculares, de conteúdos e programas de ensino sobre o combate às diferentes formas de racismo, viabiliza que a prática comprometida da luta contra as formas de preconceitos tenha respaldo e reconhecimento jurídico. "Sabe-se que o professor é indiscutivelmente um dos protagonistas centrais no processo de escolarização dos alunos e nas inovações que são implementadas para melhorar esse processo e alcançar um melhor resultado para a educação de nosso país" (Aranda, 2011, p. 304). Aranda endossa o importante papel dos professores dentro do processo de socialização infanto-juvenil, sobretudo quando os discentes aprendem juntos a seus docentes valores morais e ético que orientarão a vida sociais futuras. Logo, é crucial a formação crítica dos docentes para o fortalecimento da desconstrução das práticas de racismo que se encontram sutilmente naturalizadas no cotidiano escolar.

Conforme discute Chávez (2015), baseado em sua pesquisa sobre as ideologias racistas no processo de ensino-aprendizagem em matemática, o preconceito atravessa a relação professor-aluno. Especificamente, trata-se de uma hierarquização racial na classificação dos alunos mais e dos menos propícios ao aprendizado, ou seja, alunos branco e mestiços seriam mais hábeis a matemática que estudantes negros. Segundo o autor, haveria uma naturalização dos fatores de manutenção do fracasso escolar quando essas classificações impedem o exercício crítico por parte das instituições de concepções e valores arraigados nas relações ali existentes. Assim, o próprio "sucesso" escolar dos alunos encontra-se condicionado pelo tipo de expectativas que os professores atribuem aos discentes; no caso de alunos brancos e mestiços, boa aprendizagem e para alunos negros, poucos rendimentos.

Especificamente no Brasil, vale lembrar, as questões raciais ganharam maior destaque em termos de lutas e resistências com a implantação das políticas de cotas em 2012. Conforme discutem Paula, Almeida e Giorgi (2018), com a implementação da referida política, as práticas de segregação de preconceito têm ganhado novas configurações dentro das relações escolares. Segundos as autoras, mesmo inseridos nas escolas profissionalizantes federais, anteriormente dominada por brancos e por alunos de elevado poder aquisitivo, os alunos negros e pessoas de origem de escolas públicas sofrem racismo por diferentes formas: seja pelas velhas formas de estigmatização e violências depreciativa, seja por sutis formas da diferenciação do alunato ao serem classificados como "cotista" e "aluno negro". As autoras denunciam a persistência de formas de racionalidade que minimizam a condição de vida de negro e pobres, sobretudo quando esses indivíduos são reduzidos a identidades, conceitos e estigmas.

Entretanto, segundo Maggie (2006), a própria política de cotas traz em si indícios de discriminação. 
Ao estudar jovens de escolas públicas do Rio de Janeiro, por meio de pesquisa etnográfica, as questões de discriminação racial de negros e pardos impactam dentro das relações intraescolares sobre as relações de sociabilidade das relações fraternais e amorosas nos estudantes quando, por exemplo, não escolhem negros e pardos como seus parceiros amorosos. Entretanto, a autora sinaliza que o processo de judicialização das questões raciais, como a regulação das cotas, endossa formas de segregação entre os estudantes ao distinguir grupos raciais dentro do espaço escolar. Segundo a autora, existe uma responsabilização sobre os jovens frente à legislação, mas, com poucas estratégias de transformação da cultura em termos macrossociais, há uma perpetuação das formas de racismo. Logo, a autora questiona quais seriam os limites das políticas de cotas frente às formas de racismo que ainda podem prevalecer em função da diferenciação de grupos que a própria política social prescreve.

As questões dos racismos dentro da escola são constituídas por diferentes prismas advindos dos diferentes sujeitos que compõem a comunidade escolar. Trata-se de reconhecer que, mesmo com efetividade que as políticas prescrevem - desde a ordem curricular até a garantia de acesso a ensino superior-, devemos evidenciar que o racismo mantém-se pelas práticas, concepções e valores vividos e (re)produzidos, o que, no caso do espaço escolar, implica nas formas como os grupos não-brancos serão incluídos e/ou excluído socialmente (Cruz, 2014).

\section{Metodologia: curso de formação de jovens pesquisadores}

Trabalharemos aqui a discussão sobre a estratégia da pesquisa-intervenção (PI), articulada ao referencial teórico-metodológico da Critical Participatory Action Research (CPAR), que balizou a construção de uma pesquisa participativa com estudantes do ensino médio de uma escola pública de Fortaleza (CE) em que os próprios jovens eram pesquisadores no processo de pesquisa, potencializando o compromisso ético-político dos alunos com o cotidiano escolar. Elencamos discutir o processo de construção de pesquisa de um grupo de alunos cuja temática tratava de questões raciais.
Adotamos a PI como caminho de pesquisa quando elegemos o processo de investigação que rompe com o modelo representacional do saber e com a neutralidade do pesquisador e da não-narrativa das transformações que toda pesquisa está suscetível. Desse modo, a PI dentro de um viés de pesquisa participativa nos sugere analisarmos as forças que compõem o campo micropolítico do cotidiano, isto é, as teias discursivas, as relações sociais e as pretensas verdades naturalizadas (Aguiar \& Rocha, 2007; Rocha \& Aguiar, 2003).

Tendo em vista que a pesquisa, segundo Appadurai (2006), não deve ser exclusividade dos contextos acadêmicos, qualquer pessoa tem 0 direito de organizar uma forma de conhecer algo que ainda não se conhece completamente, produzindo assim um conhecimento singular. Foi a partir dessa perspectiva que balizamos a nossa relação com os jovens secundaristas. Como eles poderiam se tornar investigadores, pesquisadores de seu próprio cotidiano escolar?

Considerando nossa experiência prévia com a metodologia da PI (Miranda, Oliveira, Shioga, \& Rodrigues, 2016; Miranda, El Khouri, Souza Filho, 2017; Miranda, Oliveira, Souza Filho, \& Souza, 2018), articulamos a teoria da CPAR propondo uma descolonização do conhecimento. O enfoque da produção do saber em conjunto com as pessoas marginalizadas da CPAR vai ao encontro da proposta ética de "pesquisarCOM" da PI, incentivando a coparticipação entre universidade e sujeitos da comunidade escolar, atuando enquanto copesquisadores do seu cotidiano (Miranda, Fine, Torre \& Cabana, 2018). A Critical Participatory Action Research (CPAR), desenvolvida nos países de língua inglesa, mas com forte influência de pesquisadores latino-americanos - a exemplo de Paulo Freire; Martín Baró e Fals-Borda (Torre, Fine, Stoudt, \& Manoff, 2017) problematiza o lugar do sujeito-pesquisado, propondo que todo o processo da pesquisa seja construído coletivamente: pesquisadores universitários trabalham ao lado de pesquisadores da comunidade no desenho, coleta de dados, análise e disseminação da pesquisa ${ }^{1}$ " (Sandwick et al., 2018, p. 3, tradução nossa).

Corroboramos com a ideia de Miranda et al. (2016, 2018) de que, ao habitar o território escolar, posicionamos uma relação entre universidade e escola como um catalisador de formação do saber

${ }^{1}$ No original: "university researchers work alongside community researchers in design, data collection, analysis, and dissemination" (Sandwick et al., 2018, p. 3). 
mútua, onde se coloca "o desafio de trabalhar com a escola, não para levar o saber acadêmico para além dos muros da universidade, como muitas vezes é vista a extensão, mas pautada numa relação de troca, de diálogo" (Miranda, Oliveira et al., 2018, p. 311). Esta postura ético-política de fazer pesquisa possibilitou que nossas atenções e ações de trabalho tivessem como pauta uma desconstrução vertical do saber daquele que o detém sob outrem.

Temos como objetivo analisar o processo de

pesquisa sobre racismo com jovens estudantes de ensino médio de uma escola pública de Fortaleza, operada a partir de uma PI em articulação com a CPAR. Interessamo-nos por trabalhar em conjunto com os jovens por meio de uma perspectiva de sermos pesquisadores no "chão da escola" sob mesmo ethos de pesquisa. Com isso, concebemos dois planos (platôs) que se articulam: a "pesquisaCOM" (Moraes \& Arendt, 2014; Ribeiro et al., 2016) e o "escreverCOM" (Miranda \& Mourão, 2016); o primeiro como um ethos político e o segundo como uma narrativa inacabada dos acontecimentos. Nessa mesma direção, ainda enquanto pesquisadores de uma universidade pública, mantivemos uma curiosidade de aprender junto com os alunos em seus próprios desafios, de como fazer a pesquisa e, ainda, de como se intitular pesquisador, uma vez que esse status é reproduzido corriqueiramente no ensino superior (Miranda, Oliveira et al., 2018).

Entendemos que o cotidiano escolar éatravessado por uma polissemia de vozes e singularidades e, nesse contexto, as relações de poder estão presentes produzindo modos de subjetivação e práticas discursivas. Consideramos o discurso como não-estático, não um produto acabado, mas um processo, uma operação de forças e saberes que habitam o território e os sujeitos (Foucault, 2014). A partir disso, essas práticas discursivas e não-discursivas que são dizíveis e visíveis se colocam como acontecimentos analisadores, isto é, feixes de memórias, dizeres, paisagens e os modos de ser, ou até mesmo aquilo que é impensado, mas, que no cenário da pesquisa, produzem análise.
Ou seja, são "catalisadores de sentido, expõem o saber e o não saber de uma sociedade sobre si mesma e, poderíamos dizer, desnaturalizam o existente, suas condições, e, ao realizar análise, desestabilizam a cena natural de um cotidiano que nos parece estático" (Aguiar \& Rocha, 2007, p. 656).

Quando tratamos uma pesquisa para além de seu rigor metodológico e rompemos com a tradição positivista, buscamos dialogar seu atravessamento ético e político, reverberando um debate rigoroso do delineamento que se implica com as transformações do cotidiano, das relações sociais e dos processos de subjetivação (Colaço, Adrião, \& Menezes, 2018). Ainda dentro de um rigoroso caminho metodológico de investigação, propomos uma caminhada com uma atenção à espreita dos movimentos institucionais escolares a partir de um curso de formação de jovens pesquisadores. Com isso, iniciamos a inserção em campo.

O processo de inserção na escola foi possível por meio do próprio interesse do núcleo gestor de que o curso fosse oferecido em sua unidade escolar. Este engajamento foi possível por meio de uma divulgação do curso em uma reunião do Departamento de Psicologia da universidade em que parte do núcleo gestor estava presente, quando fomos convidados a desenvolver o projeto na escola. Nesta cena houve previamente o aceite da parceria entre a escola e o grupo de pesquisa. Entendemos que esse processo é analisador, uma vez que, como de costume, o movimento é inverso, neste caso a escola é protagonista, e nos aponta para como a demanda da instituição na temática é construto de pautas, interesses e implicação da comunidade escolar.

A pesquisa-intervenção intitulada "Educação, modos de subjetivação e formação de jovens pesquisadores da micropolítica do cotidiano escolar"2 realizada, com articulação ao projeto de extensão "É da Nossa Escola que Falamos", construiu uma intervenção micropolítica, por meio do curso "Jovens pesquisadores da micropolítica do cotidiano escolar”, propiciando um espaço para reflexão na

\footnotetext{
${ }^{2}$ Pesquisa aprovada pelo Comitê de Ética sob parecer nº 3.227.767.

${ }^{3}$ Curso cadastrado na Pró-Reitoria de Extensão com duração de 30 horas, distribuído em 27 horas presenciais e 3 horas não-presenciais. Cada atividade presencial teve duração de 2:30 horas e meia semanais, distribuídas em 9 encontros. A carga horária não presencial foi distribuída ao longo do curso em atividades, tais como a execução de: atividades on-line e, a aplicação do instrumento da pesquisa. Todos os encontros do curso foram gravados em áudio e vídeo como fonte de dados para a pesquisa. Segue-se a ementa do curso: A função da escola na contemporaneidade; $\mathrm{O}$ direito democrático à pesquisa; $\mathrm{O}$ estudante como agente político do cotidiano escolar; $\mathrm{O}$ que inquieta os jovens na atualidade; A criação de uma pesquisa feita COM jovens e COM a escola; como construir um projeto de pesquisa: tema, objeto, objetivos, aporte teórico, metodologia, análise e resultados; e criação de um produto de divulgação da pesquisa.
} 
escola. O curso contou com a participação de aproximadamente 40 alunos do segundo ano do ensino médio separados em duas turmas, uma para o turno da manhã e outra para o turno da tarde, assegurando a atividade no contraturno. Os secundaristas foram divididos em sete subgrupos, agrupados conforme interesse comum em tema para pesquisar. Trabalhar a formação crítica de pesquisa acerca das inquietações sobre as dinâmicas escolares corrobora para a formação política de sujeitos que participem produzindo conhecimento sobre seu contexto.

A escola em questão, referência de ensino público na cidade de Fortaleza, dispõe de uma arquitetura singular onde, ao redor das salas de aula, existe um jardim central. Com a possibilidade de ingresso por meio das políticas públicas de cotas nas universidades, o perfil socioeconômico dos alunos diversificou, sendo procurada por estudantes de diversas origens sociais, inclusive por aqueles advindos do ensino fundamental em escola particular. Em 2018, a escola possuía um pouco mais de 2000 alunos (Instituto Nacional de Estudos e Pesquisas Educacionais Anísio Teixeira [Inep], 2018) de diversas localidades da cidade, contendo apenas turmas de ensino médio nos três turnos. Trata-se de uma escola engajada politicamente, com histórico de enfrentamento aos preconceitos de gênero, sexuais, sociais ou raciais. Neste caso, há no calendário letivo projetos direcionados, por exemplo, a Semana da Consciência Negra, acompanhada pela equipe de pesquisa, onde pudemos observar o engajamento de alunos e professores discutindo a temática de maneira que não fossem apenas seminários expositivos de conteúdo. Ao habitarmos o local, pudemos visualizar alunos de uniforme customizado, cartazes afixados nas paredes com problematizações sobre o tema e compreendemos o engajamento prévio da escola como enriquecedor para nossas problematizações. A escola mostrou-se implicada com a nossa presença em seu cotidiano, traduzido, por exemplo, na inserção do curso no cronograma da reserva da sala de estudos, local dos encontros, e nos quarenta almoços semanais ofertados para os alunos e alunas inscritos na formação, além da curiosidade constante sobre o trabalho que estávamos desenvolvendo.

Mergulhados no cotidiano escolar e na potência do encontros com os jovens, operamos nossas ferramentas teórico-metodológicas; habitando o cotidiano da escola por meio de conversas informais, da produção de diários de campo escrito pelos jovens e pelo grupo de pesquisa da universidade, de grupos de discussão durante os encontros e de passagens em sala de aula. Estas atividades, junto com o próprio curso formativo, se constituíram como dispositivos necessários para fomentar a construção de análises da temática sobre questões raciais, a comunidade escolar e o grupo de pesquisa.

Cada momento do curso era composto por atividades mistas, ou seja, expositivas, exploratórias do espaço escolar e atividades práticas, por meio de dinâmicas, trabalhos manuais e grupos de discussão. Buscamos, junto com os jovens, tornar plural as abordagens dos encontros e, por isso, mantivemos um momento de avaliação do dia e da experiência em grupo.

Conforme foi dito, a escola em que os pesquisadores universitários estavam inseridos é referência entre as escolas de ensino público de Fortaleza, e tem um posicionamento político e crítico forte frente ao enfrentamento das questões raciais. Seu microcotidiano escolar encontra-se atravessado por questões raciais, onde alunos de diversas origens, sociais e raciais convivem e debatem sobre estas questões no dia a dia institucional. Muitas vezes, há tensionamento neste debate, como nos projetos e eventos produzidos pela escola - como a Semana de Consciência Negra - ou mesmo debates sobre alunos egressos contemplados ou não pela política de cotas de ingresso no ensino superior.

A seguir será exposto o debate do processo de pesquisa que indagava sobre questões raciais construído pelo subgrupo: "Como quebrar os padrões sociais?”, título dado pela própria equipe, composta por quatro alunos, dos quais dois homens e duas mulheres. 


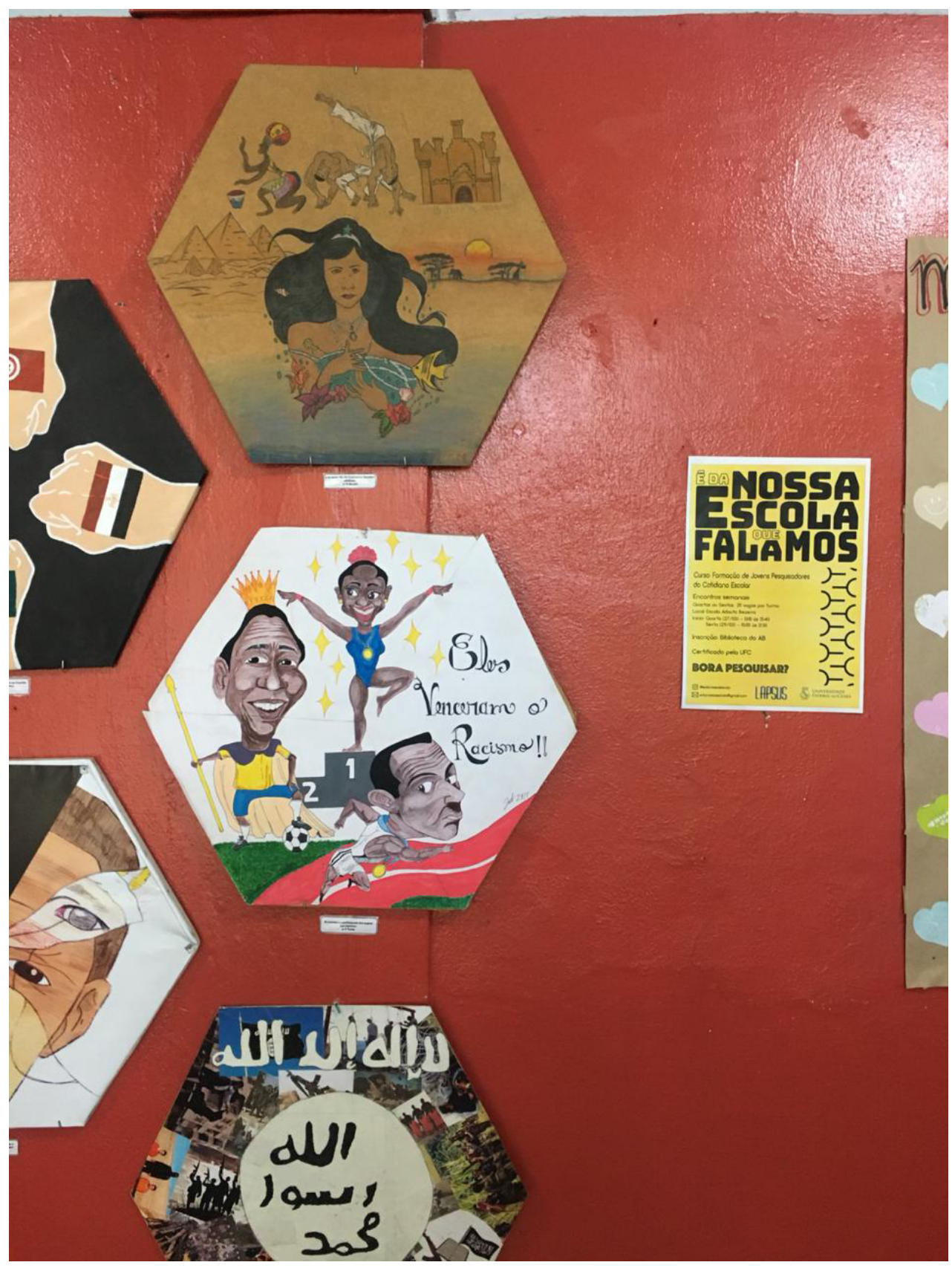

Figura 1

Quadros confeccionados pelos alunos da escola na Semana da Consciência Negra [eles venceram o racismo!].

\section{Resultados: escola e universidade na invenção de uma pesquisa}

No primeiro dia, de nervosismo dos que entram na escola e dos que recebem o "pessoal da universidade", foi a oportunidade para nos conhecer; iniciamos o curso preocupados em conhecer nossos colaboradores. Formamos duplas onde cada um deveria entrevistar alguém que tivesse pouco contato. As questões propostas foram: "Quais são suas expectativas? Quais são as suas contribuições para o curso?" e uma pergunta livre. Nesse momento, as expectativas dos estudantespesquisadores giraram tanto em torno da Psicologia que habitava e escola e do interesse em uma faculdade no futuro, quanto das próprias pesquisas que poderiam desenvolver: “. . . quando os alunos foram apresentar suas duplas já era possível extrair algumas coisas das curiosidades que respondiam, tinha questões que envolviam ser a favor ou não da legalização do 
aborto, perguntas sobre religião, perguntas de cunho ideológico e tudo isso ..." (Diário de campo de A.P., 27 de março de 2019). Após esse momento, apresentamos e explicamos o Termo de Consentimento Livre e Esclarecido (TCLE) e o Termo de Assentimento (TA) como aspectos legais da pesquisa.

Em seguida, apresentamos aos estudantes quatro definições do que é pesquisa, com a proposta de discutir os conhecimentos dos mais gerais até os mais específicos sobre a pesquisa-intervenção. Posteriormente, realizamos a última dinâmica do dia: "pedimos que escrevessem temas de interesse que eles conectam com o 'cotidiano escolar'. Recebemos e avisamos que esses últimos seriam trabalhados no próximo encontro, já que será mais explorado o tema do cotidiano escolar" (Diário de campo dos pesquisadores, 27 de março de 2019). Tivemos ao todo 116 ideias e temas sugeridos.

No encontro seguinte, com a proposta de formar grupos e temas de pesquisa, apresentamos uma síntese de 63 temas, com base nos sugeridos anteriormente. Distribuímos esses temas em uma mesa e pedimos que os estudantes escolhessem cinco temas de seu interesse. Logo após uma apresentação das escolhas individuais, solicitamos que os alunos procurassem formar grupos de pesquisas, seja por afinidade pessoal seja por temas de pesquisa. Na formação do grupo que analisamos no presente artigo, os temas escolhidos foram: influência da colonização; preconceito; aborto: legalizar ou não legalizar?; quebra de tabu; a dita democracia que muitas vezes não é verdade; cultura: respeito às diferenças; bullying; depressão; crime virtual; padrão de beleza; suicídio; prática da autoestima; cotas raciais e sociais; e precariedade nas escolas públicas. Solicitamos que os integrantes criassem o nome para sua equipe de pesquisa. O nome elegido foi "Como quebrar os padrões sociais?”, que tentava acolher a heterogeneidade dispersiva de tantas questões distintas que os mobilizava. No entanto a questão do racismo era desde o início, discursivamente enunciada:

... o nome já diz, é um pouco autoexplicativo, é uma pesquisa, é um projeto que a gente busca pesquisar sobre temas que estão no nosso cotidiano escolar, como o meu é, como é de outro grupo aqui. Bom, a minha equipe é como quebrar os padrões sociais, a gente está buscando pesquisar mais o lado do preconceito racial dentro da escola (Aluna, jovem pesquisadora).
Para uma maior delimitação acerca do objeto a ser pesquisado pelos alunos em seu cotidiano escolar, construímos coletivamente palavras-chaves e perguntas de partidas da pesquisa de cada equipe, estruturando o que mais inquietava o grupo na temática escolhida e delineando ainda mais os problemas de pesquisa. O grupo escolheu como palavras-chaves de pesquisa: racismo, desigualdade, preconceito e bullying. Como primeira estratégia, foi requisitado aos alunos a dramatização de uma cena, a fim de demonstrar a preocupação central da equipe.

O grupo "Como quebrar os padrões sociais?" encenou duas situações fictícias onde ocorriam casos de racismo dentro e fora do espaço escolar. Em uma das situações, uma pessoa negra é menosprezada e inviabilizada em uma seleção para emprego. Já na cena dentro da escola, os alunos representam uma sala de aula onde os estudantes, durante uma aula de história sobre a escravidão no Brasil, caçoam de uma colega negra, que tenta ignorar, porém acaba saindo da aula em busca de ajuda na coordenação. Quando questionados sobre a ocorrência desse tipo de episódio dentro da escola, apenas um aluno afirmou já ter visto esse tipo de cena ocorrendo na instituição, mas todos concordaram que isso ocorre apenas entre alunos, e que os professores não costumam ter essas práticas. Também foi enfatizado por eles a sutileza pela qual ocorre o racismo, não sendo muitas vezes tão explícito. A equipe finalizou com a pergunta "Como o racismo atualmente atinge os alunos negros e pardos dessa escola?”, alinhando e afunilando o que e com quem desejavam pesquisar.

Desenvolvemos ao longo do curso de formação algumas ferramentas metodológicas com os jovens que possibilitaram articular um processo de pesquisa com base nas singularidades do grupo e a partir de suas demandas de viabilidade operacional e instrumentos, tensionando a uma "pesquisaCOM" e sua radicalidade de participação. Assim, operamos com uma política inventiva do acompanhamento de processos, pois consideramos que a invenção na sua dimensão processual, desviante de uma lógica abstrata e representacional, nos convoca a problematizar os efeitos produzidos por nossas intervenções em seu âmbito ético e político (Kastrup, 2012).

Embora tentamos não direcionar, não sugestionar, há sempre uma fagulha de inquietação em perguntar: "na escola da qual falamos, o tema 
escolhido por vocês se movimenta nas conversas informais, nos horários de aula e nos encontros entre pares?". Se "é da nossa escola que falamos", certamente eles são o porta-voz dessa pergunta, na qual incessantemente suas pesquisas nos revelam de um cotidiano escolar que permeado nos temas, respondem a pergunta sem precisarem ser interpelados por nós (Diário de campo do grupo de pesquisadores da universidade, 2019).

Habitando o território escolar, consideramos a relevância da assinatura do TCLE em sua dimensão institucional e ética, mas também explicativa do curso de formação. A partir disso, criamos, em conjunto, estratégias de diálogo sobre as ferramentas metodológicas comumente trabalhadas nos cenários de pesquisa, tais como a observação-participante, a técnica da entrevista, o uso dos questionários com perspectiva quantitativa e qualitativa e o funcionamento do grupo focal.

Utilizamos o diário de campo durante o curso, o que teve uma centralidade em nossas intervenções metodológicas, pois, assim como o grupo de pesquisa da universidade, os estudantes também desenvolveram suas próprias narrativas escritas do cotidiano da pesquisa num caderno que passou acompanhar as atividades do grupo. Na capa do diário de campo do grupo podemos ver alguns significantes que atravessavam a pesquisa do grupo: psicologia; nome do projeto; nome da escola (borrado para não gerar identificação); pesquisa; cultura; diferença; e racismo. Há também uma foto em que pesquisadores da universidade e da escola estão juntos em atividade. Marcadores discursivos da forma de ver e sentir a pesquisa conduzida pelo grupo.

Nossos movimentos de produzir tensionamentos sobre o caminho metodológico de uma pesquisa fizeram com que coletivamente inventássemos, por meio de atividades práticas elúdicas, maneiras de conhecer e debaterametodologia.Sendo assim, para a observaçãoparticipante circulamos pela escola com um olhar refinado, salientando observar e capturar aquilo que não é conversado no cotidiano e que passa despercebido, por exemplo. Criamos cenas teatrais que abordassem o uso da entrevista como ação dirigida para debater o roteiro e o improviso. Criamos, debatemos em grupo, e os estudantes responderam um questionário quanti-quali para conhecerem e se apropriarem de formatos mistos de questionar e responder itens. Por último, em nossos próprios encontros no curso de formação, lapidamos uma centralidade nos diálogos em grupo como intervenção da escuta e fala dos sujeitos.

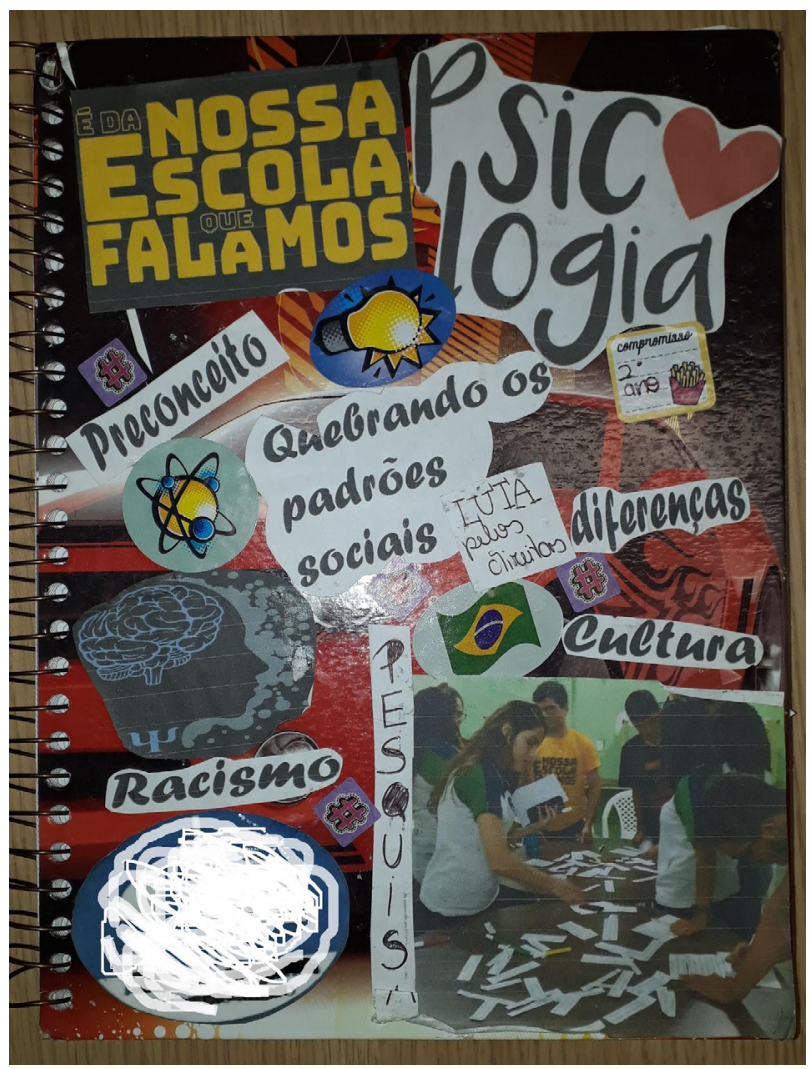

Figura 2

Capa do caderno que operou como diário de campo do grupo de jovens pesquisadores.

Caminhando com esse percurso, o grupo de jovens pesquisadores criou seu próprio instrumento de pesquisa, optando pelo uso do questionário sob o modo on-line, utilizando a ferramenta do Google Forms, que permite criar, responder e tabular os resultados por meio de gráficos, tabelas e texto. A partir da temática desenvolvida na pergunta de partida "Como quebrar os padrões sociais?” e com as questões raciais explicitadas, um questionário de perguntas objetivas e subjetivas foi aplicado no corpus on-line. Centrados na sua escolha, construíram suas perguntas, e divulgaram a proposta de pesquisa, a temática e o período para que os alunos previamente selecionados por turmas pudessem responder ao formulário. Foi escolhida uma turma para cada ano do ensino médio do turno matutino. Por ter um caráter on-line, os estudantes pesquisadores enviaram para os alunos via rede social o link de acesso ao questionário, totalizando 43 respostas. 
Após a aplicação do questionário de pesquisa, realizamos um encontro para a análise dos resultados. Inicialmente, realizamos em conjunto com a equipe a leitura das respostas quantitativas e qualitativas do questionário e, em seguida, foram criadas categorias pelo grupo de jovens pesquisadores a partir das respostas qualitativas que se assemelhavam em seu conteúdo como por exemplo: cotas raciais não é esmola, racismo etc.

A partir da análise dos resultados, pode-se traçar o perfil do público que respondeu a pesquisa: em relação à faixa etária, $39,5 \%$ de 15 anos e $37,2 \%$ de 16 anos; em relação ao gênero, $63,4 \%$ eram do gênero feminino, 31,7\% do gênero masculino; em relação à etnia, $53,5 \%$ se autodeclararam pardos, $23,3 \%$ brancos e 18,6 \% negros; e, em relação à renda familiar, 39,5\% dos agrupamentos familiares recebiam de um a três salários mínimos.

Outro dado a ser considerado é que $30,2 \%$ dos respondentes afirmaram ter sofrido algum tipo de preconceito racial, tais como: preconceito em relação ao cabelo por ser cacheado; ter escutado expressões/ apelidos pejorativos como "você é tão bonita para ser negra", "macaca", "café com leite”, "meio mexicano meio americano" e "miserável" por ser negro; e discriminação por não ter boas condições financeiras. Um aspecto relevante é que algumas pessoas responderam que não se sentiam à vontade para falar sobre o preconceito que sofreram.

É importante ressaltar que $65,1 \%$ das pessoas não percebem nenhuma diferença de tratamento entre alunos negros/pardos e alunos brancos dentro do ambiente escolar, enquanto $34,9 \%$ percebem diferença de tratamento. Assim, apesar da escola estar atenta no combate ao racismo e promover ações contra o preconceito racial, como exemplo, a Semana de Consciência Negra, os dados apontaram que existe preconceito racial dentro da escola, mesmo não configurando maioria das respostas. Tal questão mobilizou os alunos a quererem refletir esta situação com seus professores:

13 pessoas falaram que sofreram muito preconceito ... que a gente vai fazer na nossa dinâmica com os professores, explicar a importância de ter essa conversa com o aluno, porque dentro desses 13 não foram todos que se sentiram confortáveis o suficiente pra explicarem como sofreram o racismo, da maneira que eles sofreram, e a gente achou importante colocar esses dados, e o que chocou a equipe inteira, foi daquilo que a gente falou no encontro passado, num (sic) foi? Da questão da diferença de alunos negros e pardos com brancos (Aluna, jovem pesquisadora).

No último encontro houve muita expectativa de ambos os lados. Nós, os pesquisadores universitários, concluímos o nosso curso de formação com os alunos e estávamos animados para sabermos como eles iriam finalizar esta etapa de construção e análise dos dados. Já os jovens pesquisadores da micropolítica do cotidiano escolar estavam diante da materialização de todas as ideias e investimentos lançados durante o percurso de construção da pesquisa.

Os jovens pesquisadores reuniram-se em grupo e, dispondo das respostas ao formulário, analisaram cada resposta objetiva e subjetiva e discutiram entre si os dados obtidos, dando um foco maior às perguntas qualitativas, pois estavam densas e ricas de opiniões significativas para o que a equipe investigava. Concomitantemente ao processo de discussão dos resultados obtidos, os alunos construíram um banner artesanal onde dispuseram as informações que consideraram mais importante a serem exploradas e divulgadas. As duas atividades feitas de forma conjunta possibilitaram que os alunos se dedicassem a discutir os dados mais relevantes julgados por eles, tendo um debate mais profundo e focado no objeto de sua pesquisa.

Os dados selecionados para compor o banner elaborado por eles foram: a autodeclaração de raça; se o aluno já havia sofrido algum tipo de preconceito racial; se ele recebe auxílio do governo; e se o aluno percebe alguma diferença de tratamento dentro do espaço escolar entre pessoas negras/pardas em detrimento de brancas. $\mathrm{O}$ último dado chamou a atenção dos jovens pesquisadores. Aproximadamente $35 \%$ dos alunos que responderam ao questionário percebem uma diferença de tratamento entre pessoas brancas e negras/pardas no ambiente escolar, o que é um dado significativo já que a escola tem um histórico forte de resistência na luta antirracista.

\section{Discussão dos resultados}

Como já situamos anteriormente, dentro da escola onde nossa pesquisa foi realizada, faz parte da dinâmica institucional a promoção de uma 
cultura democrática onde as situações de preconceito e racismo sejam desconstruídas e minimizadas. Não seria ao acaso que o tema, tensionado na micropolítica do cotidiano institucional, ganhasse relevo agora como objeto de uma pesquisa social realizada pelos próprios secundaristas:

Desde os tempos coloniais, o padrão social é algo imposto pela sociedade para a sociedade. Atualmente todo esse conceito não mudou. Atualmente pessoas morrem, sofrem preconceitos por serem "diferentes". Quando escolhemos sobre esse assunto, estamos no caminho da mudança, procurando cada vez mais o respeito entre populações com culturas distintas (Diário de campo do grupo de jovens pesquisadores secundaristas, 2019).

A luta contra as formas de preconceito, que a escola desenvolve com a execução de feiras, projetos e temas de aulas, se fez presente quando nossos pesquisadores-estudantes nomearam sua equipe com a questão “Como quebrar os padrões sociais?". Tal nome já enuncia o quanto eles já reconhecem, por um lado, a importância de construir e encontrar vias de desconstruir práticas de segregação e preconceitos e, por outro, demonstram suas posturas curiosas e inquietas sobre esse tema no cotidiano de seus colegas, jovens estudantes de escola pública:

A nossa pesquisa de primeira mão, a pergunta da gente era como o racismo ele atinge os alunos, pardos e negros, do [nome da escola] então a gente meio que ainda não tem uma solução e sim a forma de como o racismo ele entra na vida de cada aluno, que sofre ou não, ou que vê, participa de tal ato. Na nossa pesquisa a gente fez muita pergunta na questão de você já sofreu racismo? Se sentir à vontade, comente, e por incrivel que parece tem gente que respondeu sim, nas respostas, muitas respostas, eu acho que, eu tava olhando com a Shirley [pesquisadora da universidade] ... e tinham pessoas que não se sentiam à vontade, e mesmo sendo um colégio tão liberal, mesmo sendo um colégio que abrange tanto esse negócio do respeito, da conversa, do diálogo (Aluna, jovem pesquisadora).

Como lugar de desassossego, a pesquisa convoca as incertezas no território do outro (Amorim, 2001).
Tanto nós, pesquisadores advindos da universidade, quanto os jovens secundaristas fomos surpreendidos com parte daqueles que sofrem preconceito não encontrarem na escola um lugar de acolhimento e de luta política sobre essa questão. Outra questão que causou surpresa é que, malgrado o engajamento institucional da escola no campo macro e micropolítico de luta contra qualquer tipo de preconceito, $35 \%$ dos que responderam ao questionário percebem diferença de tratamento entre alunos brancos e pardos/negros:

Pesquisadora da universidade: Mas, me fala de quantitativo, algum número que chamou atenção?

Aluna: Ah, um número que chamou a atenção da gente foi que a gente perguntou a seguinte, assim, é, você vê diferença de tratamento entre negros, pardos e brancos [na escola]? E o que a gente tava até discutindo, a Gabi [pesquisadora da universidade] falou que foi meio contraditório o que a gente falou e a pesquisa, é que na pesquisa mostrava muitos, foi quanto o número? Mas muitas, boa parte dizia que via sim diferença de tratamento aqui no [Nome da escola], de tratamento.

Pesquisadora da universidade: Quase 35\%.

Aluna: Quase 35\% da nossa pesquisa disse que, pessoal falou que via diferença de tratamento para negros e brancos, é algo que a gente da equipe falou que não via com frequência, sabe que existe, existe, só que a gente não via com tanta frequência.

Esta discussão colocada pelos jovens pesquisadores ao analisar seus dados de pesquisa teve grande relevância nos últimos dois encontros do curso de formação, pois foram abordadas de maneira coletiva as contradições das respostas sobre o acometimento de práticas racistas na escola. Isso mobilizou a atenção dos jovens para, por um lado, a escola, que trabalha continuamente atividades de debate permanente em defesa pela diversidade e equidade, e para, por outro, os discursos dos outros alunos que sofreram racismo. Tais temas foram debatidos tanto na fase de análises de dados, quanto na exposição e apresentação da compilação da pesquisa na apresentação do banner para professores e representantes de turma. 


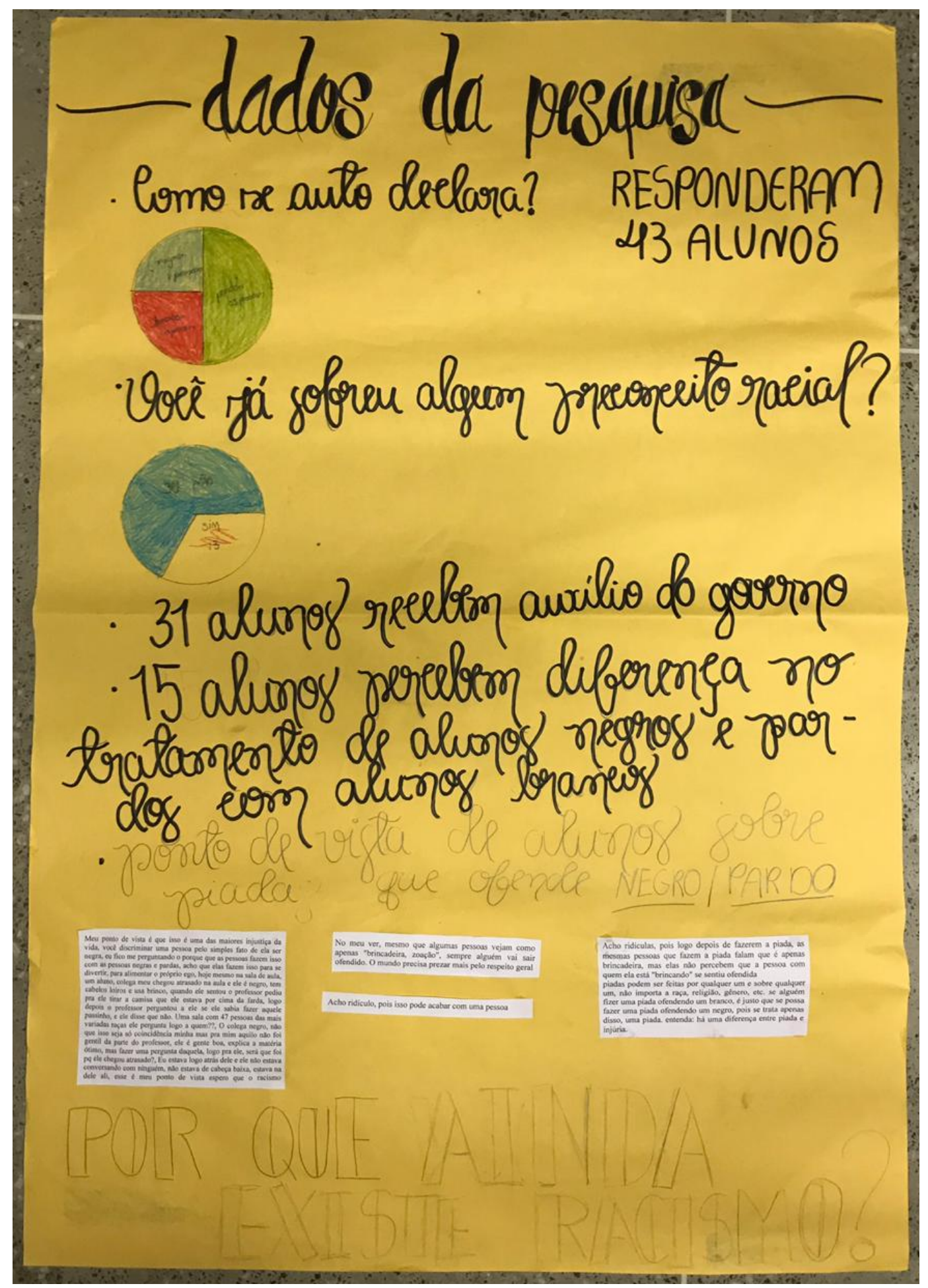

Figura 3

Banner artesanal produzido pelo grupo de jovens pesquisadores.

Esse é o nosso cartaz, eu quis deixar em preto para dar mais destaque ao nome da nossa equipe que é: “Como quebrar os padrões sociais?”, a nossa pergunta tá nessas duas linhas: "Como o racismo atinge os estudantes negros e pardos do [nome do colégio]?”. Não quis colocar o nome [do colégio] porque ia ficar muito grande então eu fiz o símbolo que geralmente fica nas blusas. Aqui a gente 
colocou o que era necessário, que o José [pesquisador da universidade] falou, que são os participantes da pesquisa que foram os alunos do $1^{\circ} \mathrm{H}, 2^{\circ} \mathrm{E} e$ o $3^{\circ} \mathrm{F}$ e aqui a equipe de pesquisadores que somos o pessoal dessa equipe, que sou eu, E., G., I. e A ... e aqui embaixo a gente colocou uma foto pra representar o grupo, de pessoas de cores diferentes, que é meio como quebrar esse racismo, e aqui tentei copiar a logo do "É da Nossa Escola que Falamos", e aqui do lado coloquei o brasão da universidade pra identificar (Aluna, jovem pesquisadora).

O momento de apresentação do processo e do resultado da pesquisa produzida pelos jovens pesquisadores se manteve num diálogo aberto e problematizador com outros alunos integrantes do curso, que também produziram pesquisas sobre outras temáticas, tais como saúde mental e pressão do vestibular e gravidez na adolescência. Tensionamos, enquanto facilitadores nesse momento, uma possibilidade de ser fomentada ações estratégicas de combate ao racismo e de temas transversais dentro do cotidiano escolar a partir de suas pesquisas. Todos os resultados foram apresentados pelos pesquisadores secundaristas para professores e gestores, que se mostraram surpresos quanto à permanência de práticas racistas no cotidiano escolar e salientaram a necessidade de intensificar ações de combate ao racismo na escola

\section{Considerações finais}

Nosso intento neste artigo foi destacar a potência política da pesquisa-intervenção com jovens pesquisadores da escola pública como uma forma de descolonizar o saber e radicalizar o caráter participativo de jovens implicados no seu cotidiano escolar. No decorrer do processo, tantos os alunos secundaristas, quanto os pesquisadores acadêmicos nos apropriamos de um certo modo de ser pesquisador e pesquisadora, construindo conjuntamente uma (com)ciência e postura ético-política com a produção de conhecimento local, promovendo uma autonomia com responsabilidade, sobre os processos de pesquisa e desencadeando um maior engajamento na transformação do cotidiano escolar.

Quando propomos radicalizar o caráter participativo, isto é, produzir com os jovens uma pesquisa em que eles mesmos fossem pesquisadores, reportamos nossas bases teórico-metodológicas, éticas e políticas à PI (Rocha \& Aguiar, 2007) e CPAR (Torre et al., 2017) para tratar esse percurso como uma possibilidade de descolonizar e produzir um saber territorializado a partir de demandas emergentes dos próprios sujeitos, das instituições e da micropolítica do cotidiano.

Colocamos o ethos de pesquisadores atuantes nos processos cotidianos, no planejamento de investigação da realidade e na proposição de estratégias de leitura das situações de discriminação, opressão e desigualdade presentes, como ocorreu em parte nas discussões dos jovens pesquisadores sobre as constatações e contradições em torno dos resultados quantitativos e qualitativos sobre as práticas racistas no território escolar.

À medida que a pesquisa dos estudantes foi se delineando, o grupo analisava os desafios envolvidos na execução, experimentando as vicissitudes envolvidas no processo. O trabalho em grupo conjuntamente com o aperfeiçoamento do olhar crítico desnaturalizaram o cotidiano em que os pesquisadores produziram seu próprio contexto, problematizando os jogos de forças presentes, fazendo com que se reconhecessem como criadores do conhecimento sobre o cotidiano institucional.

Fomentar a formação de pesquisadores e profissionais da Psicologia no contexto escolar por meio da parceria estabelecida entre gestão escolar, jovens pesquisadores e nossas demandas foi significativo para repensarmos práticas cristalizadas de produção de aspectos metodológicos, assim como a atuação na escola que não encaixasse os estereótipos da comunidade estudada apenas como informante. Importante trazer os profissionais "psi" para a educação, movidos pelas questões escolares de combate ao preconceito e ao racismo, cientes que as questões de segregação racial possuem formas e permanências no cotidiano escolar nos atravessamentos subjetivos dos atores envolvidos (Paula, Almeida, \& Gorgi, 2018)

Procuramos na "pesquisaCOM" (Moraes, 2014) fazer emergir uma relação entre escola-universidade de forma propositiva na formação ética e política de sujeitos acerca de questões raciais, principalmente por ser uma temática que não cessa de esgotar nos debates da academia. Buscamos, assim, na pesquisa, seja no seu curso de formação, seja na sua operação das pesquisas dos jovens, amplificar novos horizontes analíticos de investigação sobre o racismo. 


\section{Referências}

Abreu, M., \& Mattos, H. (2008). Em torno das "Diretrizes curriculares nacionais para a educação das relações étnico-raciais e para o ensino de história e cultura afro-brasileira e africana”: uma conversa com historiadores. Estudos Históricos, 21(41), 5-20. http://dx.doi.org/10.1590/S0103-21862008000100001

Amorim, M (2001). O pesquisador e seu outro: Bakhtin nas Ciências Humanas. Musa.

Aguiar, K. F., \& Rocha, M. L. (2007). Micropolítica e o exercício da pesquisa-intervenção: Referenciais e dispositivos em análise. Psicologia: Ciência e Profissão, 27(4), 648-663. http://dx.doi.org/10.1590/S1414-98932007000400007

Appadurai, A. (2006). The right to research. Globalisation, societies and education, 4(2), 167-177. https://doi.org/ $10.1080 / 14767720600750696$

Aranda, V. (2011). Reflexión y análisis de políticas y prácticas innovadoras a la luz de las representaciones sociales y de la necesidad de una educación intercultural en la formación inicial docente. Estudios pedagógicos (Valdivia), 37(2), 301-314. https://dx.doi.org/10.4067/S0718-07052011000200018

Chávez, L. E. (2015). “Los negros no son buenos para las matemáticas”: Ideologías raciales y prácticas de enseñanza de las matemáticas en Colombia. CS, (16), 169-206.

Colaço, V. D. F. R., Adrião, K. G., \& Menezes, J. A. (2018). Implicações políticas na pesquisa-intervenção com jovens. Revista de Psicologia, 9(1), 8-17.

Cruz, T. M. (2014). Espaço escolar e discriminação: significados de gênero e raça entre crianças. Educação em Revista, 30(1), 157-188. https://dx.doi.org/10.1590/S0102-46982014000100007

Foucault, M. (2014) A ordem do discurso. Loyola.

Instituto Nacional deEstudose PesquisasEducacionais Anísio Teixeira. (2018). Censo Escolar2018.https://www.gov.br/ inep/pt-br/areas-de-atuacao/pesquisas-estatisticas-e-indicadores/censo-escolar/resultados

Kastrup, V. (2012). Inventar. In T. M. G. Fonseca, M. L. D. Nascimento, \& C. Maraschin (2012). Pesquisar na diferença: um abecedário. Sulina.

Maggie, Y. (2006). Racismo e anti-racismo: Preconceito, discriminação e os jovens estudantes nas escolas cariocas. Educação \& Sociedade, 27(96), 739-751. https:// dx.doi.org/10.1590/S0101-73302006000300006

Miranda, L. L., \& Mourão, L. C. C. B. (2016). Escrever COM: o que isso (re)significa?. Revista Polis e Psique, 6(spe), 162-175.

Miranda, L. L., Oliveira, E. N. P., Shioga, J. E. M., \& Rodrigues, D. C. (2016). Pesquisando com jovens na escola: desafios da pesquisa-intervenção em dois contextos escolares. Psicologia Escolar e Educacional, 20(2), 245-254. https://doi.org/10.1590/2175-353920150202958

Miranda, L. L., El Khouri, M. M., Souza Filho, J. A., \& Oliveira, E. N. P. (2017). O vídeo como dispositivo na pesquisa com jovens estudantes: Contorno(s) estético-ético-político(s). Revista de Psicologia, 8(1), 53-64.

Miranda, L. L., Oliveira, P. S. N., Souza Filho, J. A. D., \& Sousa, S. K. R. B. (2018). A Relação Universidade-Escola na formação de professores: Reflexões de uma pesquisa-intervenção. Psicologia: Ciência e Profissão, 38(2), 301-315. https://doi.org/10.1590/1982-3703005172017

Miranda, L. L., Fine, M., Torre, M., \& Cabana, A. (2018). Participatory Action Research (PAR) with LGBTQ+ \& GNC youth in the United States: an interview with Michelle Fine, Maria Torre, and Allison Cabana. Revista de Psicologia, 9(1), 132-140.

Moraes, M., \& Arendt, R. (2014). Do pesquisarCOM ou de tecer e destecer fronteiras. In G. M. Tavares, M. Moraes, \& A. G. Bernardes (Orgs.). Cartas para pensar: Políticas de pesquisa em psicologia. Vitória: Edufes, 131-137.

Paula, B. A. O., Almeida, F. S., \& Giorgi, M. C. (2018). "Eu e meus alunos-cotistas na escola pública”: Racismo, ethos discursivo, discurso midiático e produção de subjetividade. Letras de Hoje, 53(3), 393-402. https://dx.doi.org/ 10.15448/1984-7726.2018.3.30988

Ribeiro, D. M., Miranda, L. L., Feitosa, G. L., Cardoso, N. F. S., Oliveira, P. S. N., \& Oliveira, T. C. D. (2016). Pesquisando com professores: a centralidade do diário de campo e da restituição em uma pesquisa-intervenção. Revista de Psicologia, 7(1), 81-93.

Rocha, M. L., \& Aguiar, K. F. (2003). Pesquisa-intervenção e a produção de novas análises. Psicologia: Ciência e Profissão, 23(4), 64-73. https://doi.org/10.1590/S1414-98932003000400010 
Sandwick, T., Fine, M., Greene, A. C., Stoudt, B., Torre M. E., \& Patel, L. (2018). Promise and provocation: Humble reflections on critical participatory action research for social policy. Urban Education, 53(4), 473-502. https://doi.org/ $10.1177 / 0042085918763513$

Torre, M. E., Fine, M., Stoudt, B., \& Manoff, E. (2017). Critical participatory action research on State violence: Bearing wit(h)ness across faut line of power, privilege and dispossession. In N. Delzin, \&Y. S. Lincoln (Orgs). Handbook of Qualitative Research (pp. 492-515). Sage.

\section{Luciana Lobo Miranda}

Professora associada IV do programa de pós-graduação em psicologia da Universidade Federal do Ceará (UFC), Fortaleza - CE. Brasil.

E-mail: lobo.lu@uol.com.br

(1) https://orcid.org/0000-0002-7838-8098

\section{Tadeu Lucas de Lavor Filho}

Doutorando em psicologia na Universidade Federal do Ceará (UFC), Fortaleza - CE. Brasil.

E-mail: tadeulucaslf@gmail.com

(1) https://orcid.org/0000-0003-2687-1894

\section{José Alves de Souza Filho}

Doutorando em psicologia na Universidade Federal do Ceará (UFC), Fortaleza - CE. Brasil.

E-mail: josefilhoss@gmail.com

(1) http://orcid.org/0000-0001-8059-9196

\section{Shirley Dias Gonçalves}

Doutoranda em psicologia na Universidade Federal do Ceará (UFC). Servidora pública na Universidade Federal do Ceará (UFC), Fortaleza - CE. Brasil.

E-mail: shirleydiasgoncalves@gmail.com

(1) https://orcid.org/0000-0002-0957-0275

\section{Thalia Araújo Bezerra}

Graduanda em psicologia na Universidade Federal do Ceará (UFC), Fortaleza - CE. Brasil.

E-mail: thaliabezerra.taab@gmail.com

(1) https://orcid.org/0000-0001-9763-7451

\section{Gabrielle Lima Feitosa}

Mestranda em psicologia na Universidade Federal do Ceará (UFC), Fortaleza - CE. Brasil.

E-mail: gabriellelimafeitosa@gmail.com

(1) https://orcid.org/0000-0003-3283-7123

Agradecimento a UFC, CAPES e FUNCAP pelas bolsas de Extensão e PIBIC (UFC) e bolsas de mestrado e doutorado (CAPES e FUNCAP).

Pesquisa contemplada pelo Edital 03/2019 FUNCAP - Auxílio para despesas excepcionais de pequeno valor.

Endereço para envio de correspondência:

Universidade Federal do Ceará. Programa de Pós-Graduação em Psicologia. Avenida da Universidade, 2762, Benfica. CEP: 60.020-180. Fortaleza - CE. Brasil. 
Psicologia: Ciência e Profissão 2020 v. 40 (n.spe), e230089, 1-16.

Recebido 14/10/2019

Aceito 17/10/2019

Received 10/14/2019

Approved 10/17/2019

Recibido 14/10/2019

Aceptado 17/10/2019

Como citar: Miranda, L. L., Lavor Filho, T. L., Souza Filho, J. A., Gonçalves, S. D., Bezerra T. A., \& Feitosa, G. L. (2020). “Como quebrar os padrões sociais?”: o racismo no cotidiano de jovens pesquisadores. Psicologia: Ciência e Profissão, 40 (n.spe), 1-16. https://doi.org/10.1590/1982-3703003230089

How to cite: Miranda, L. L., Lavor Filho, T. L., Souza Filho, J. A., Gonçalves, S. D., Bezerra T. A., \& Feitosa, G. L. (2020). "How to break social standards?": Racism in the daily lives of young researchers. Psicologia: Ciência e Profissão, 40 (n.spe), 1-16 https:// doi.org/10.1590/1982-3703003230089

Cómo citar: Miranda, L. L., Lavor Filho, T. L., Souza Filho, J. A., Gonçalves, S. D., Bezerra T. A., \& Feitosa, G. L. (2020). “¿Cómo romper los estándares sociales?”: Racismo en la vida cotidiana de los jóvenes investigadores. Psicologia: Ciência e Profissão, 40 (n.spe), 1-16. https://doi.org/10.1590/1982-3703003230089 